\title{
Early Outcomes of Osseointegration in Combat-Related Transhumeral Amputations
}

CPT Archie L. Overmann MD1,2; COL Benjamin K. Potter MD, FACS 1,2; CAPT Jonathan A. Forsberg MD, PhD 1,2,3

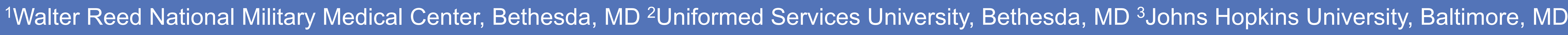

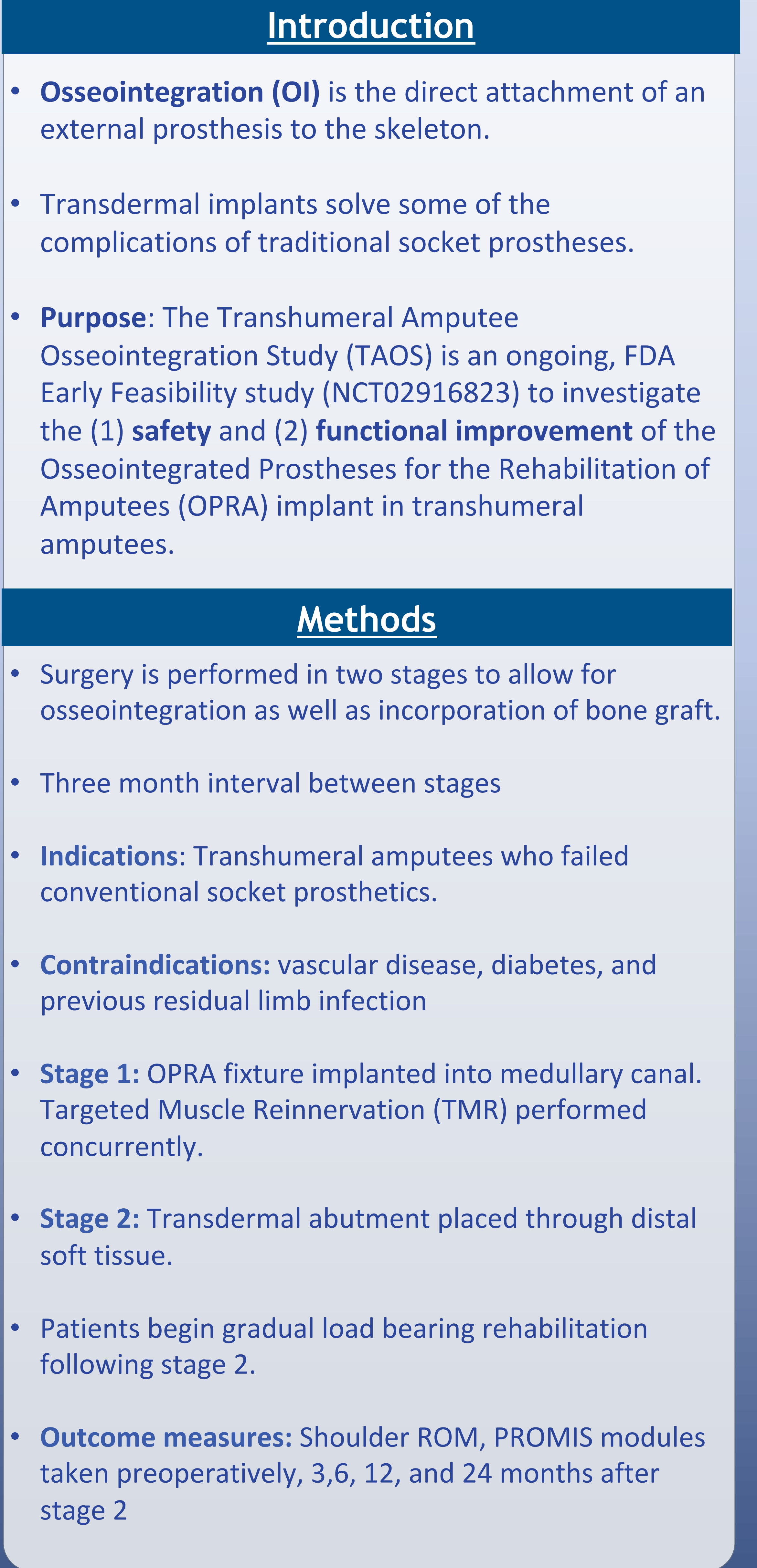
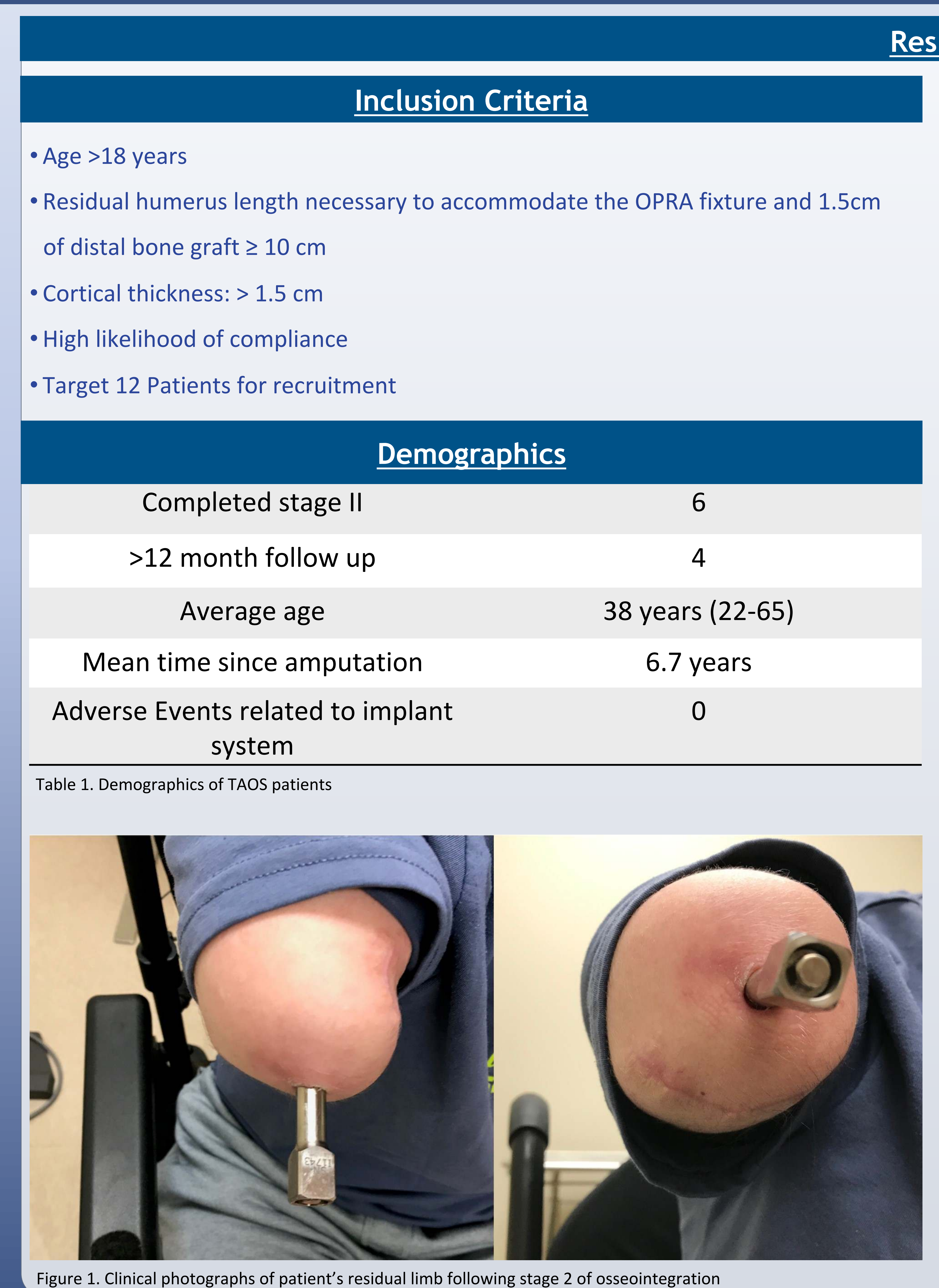

\section{$\underline{\text { Results }}$}

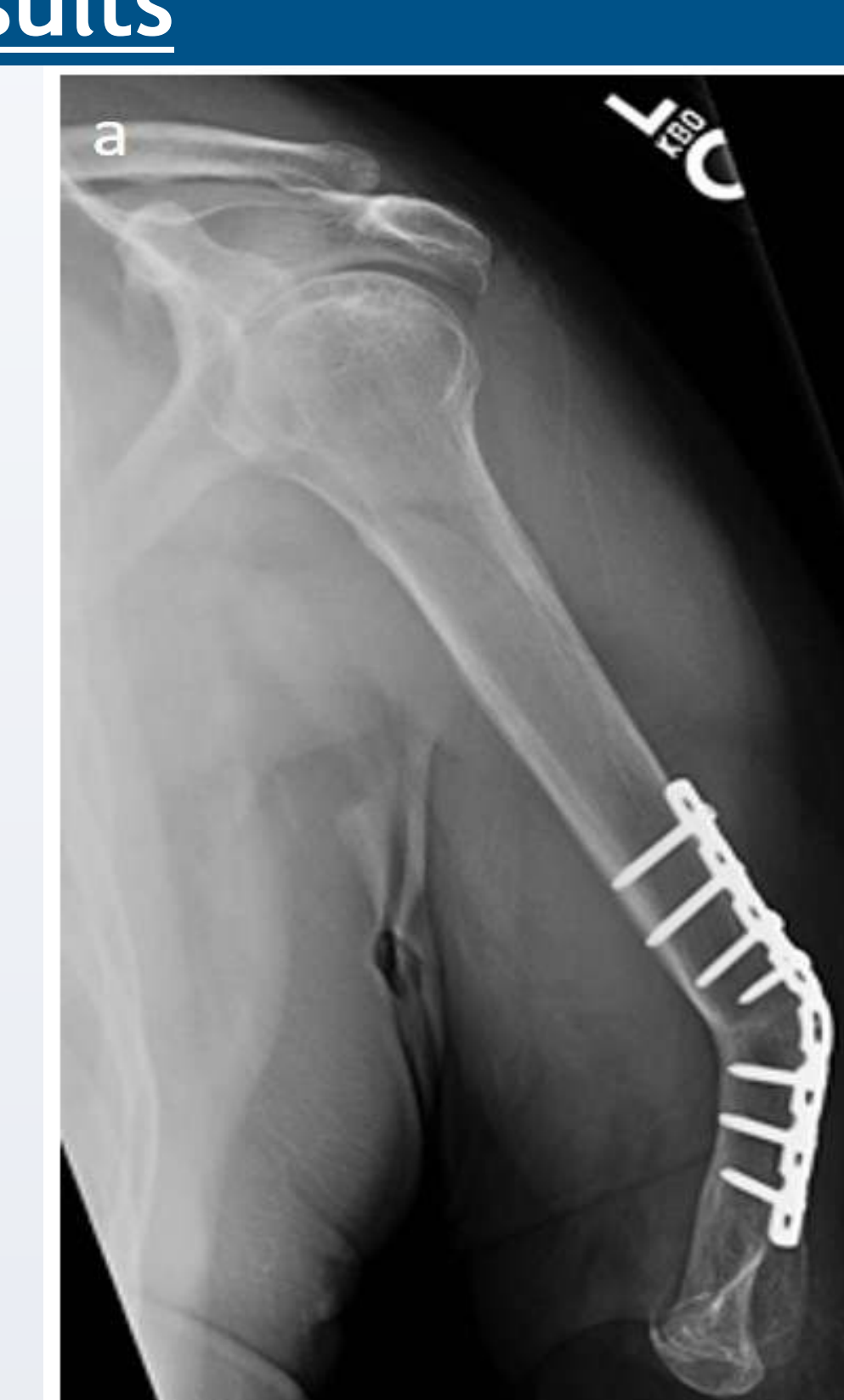

Mean Implant Use (Hours)

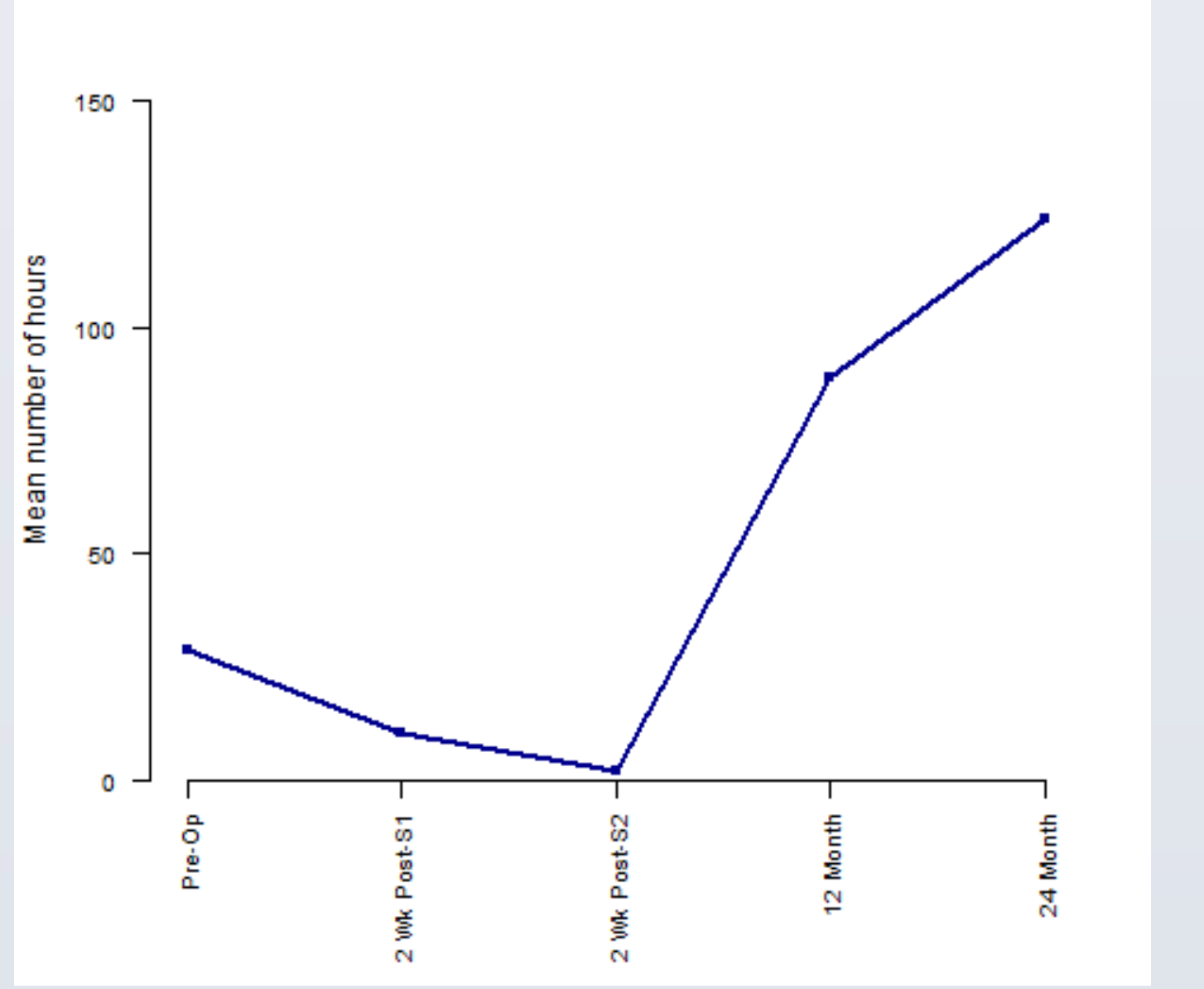

Figure 3. Mean Hours of Implant Use.

$$
\text { Mean PROMIS Scores }
$$

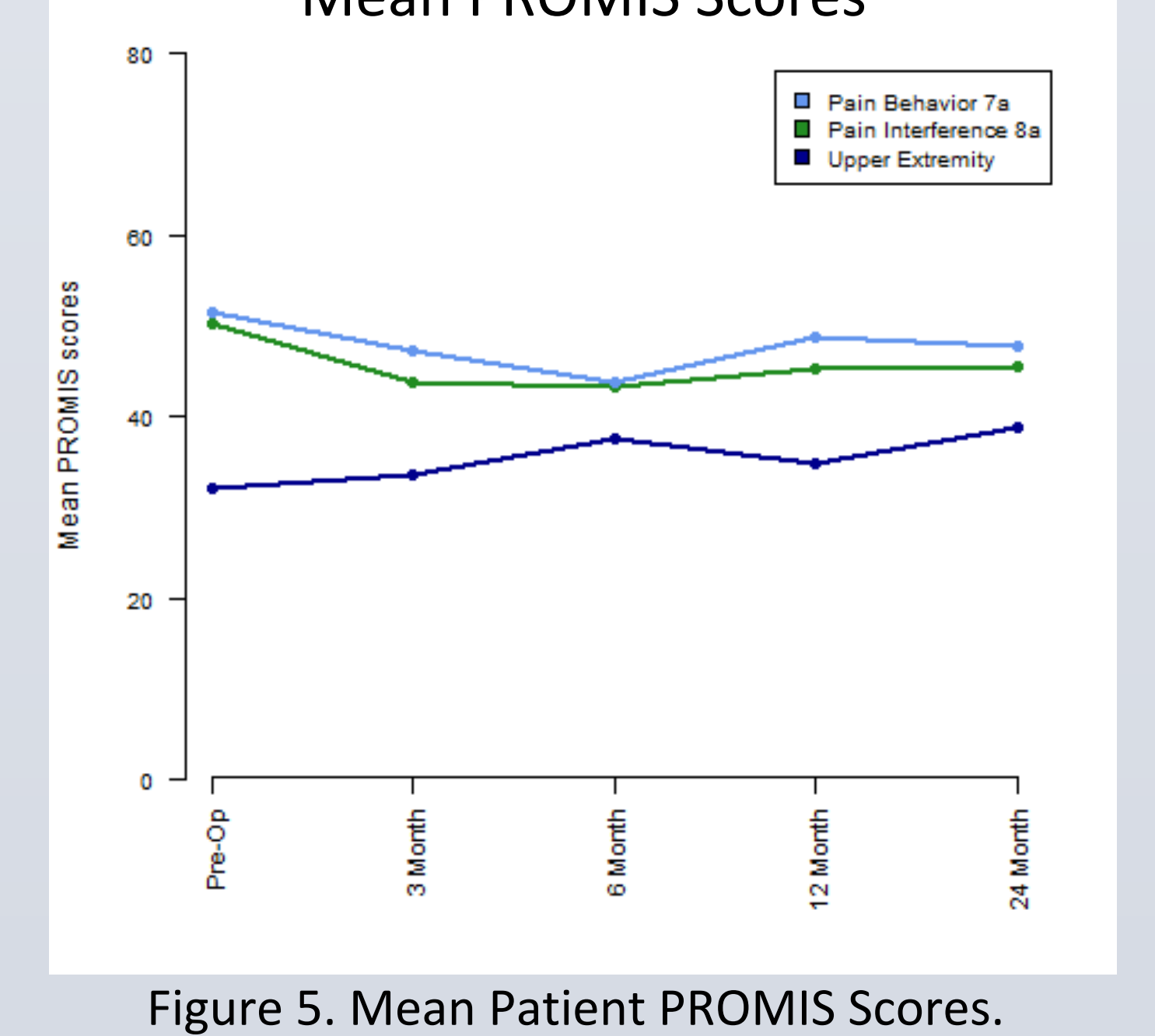

No

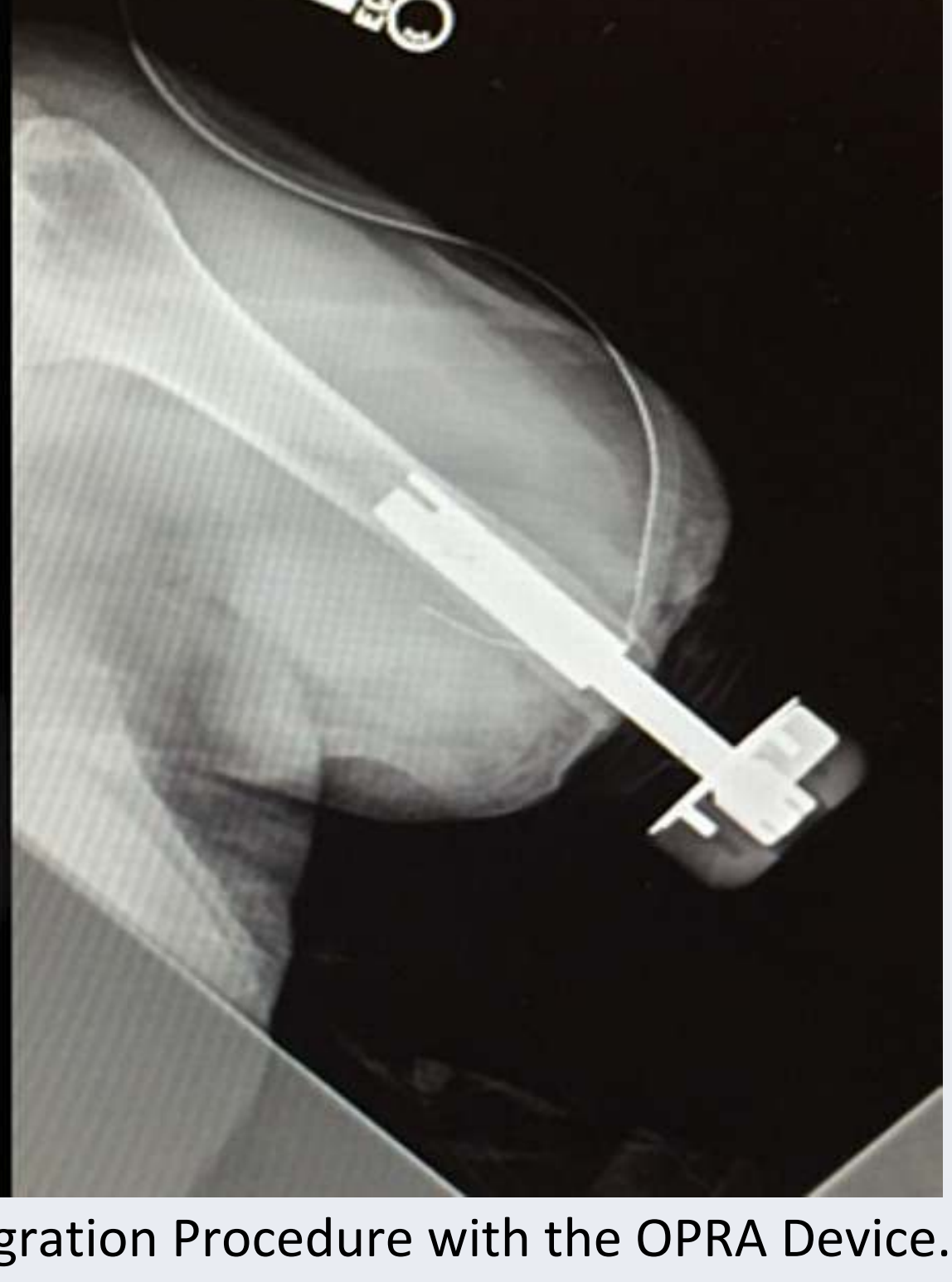

Mean DASH Scores

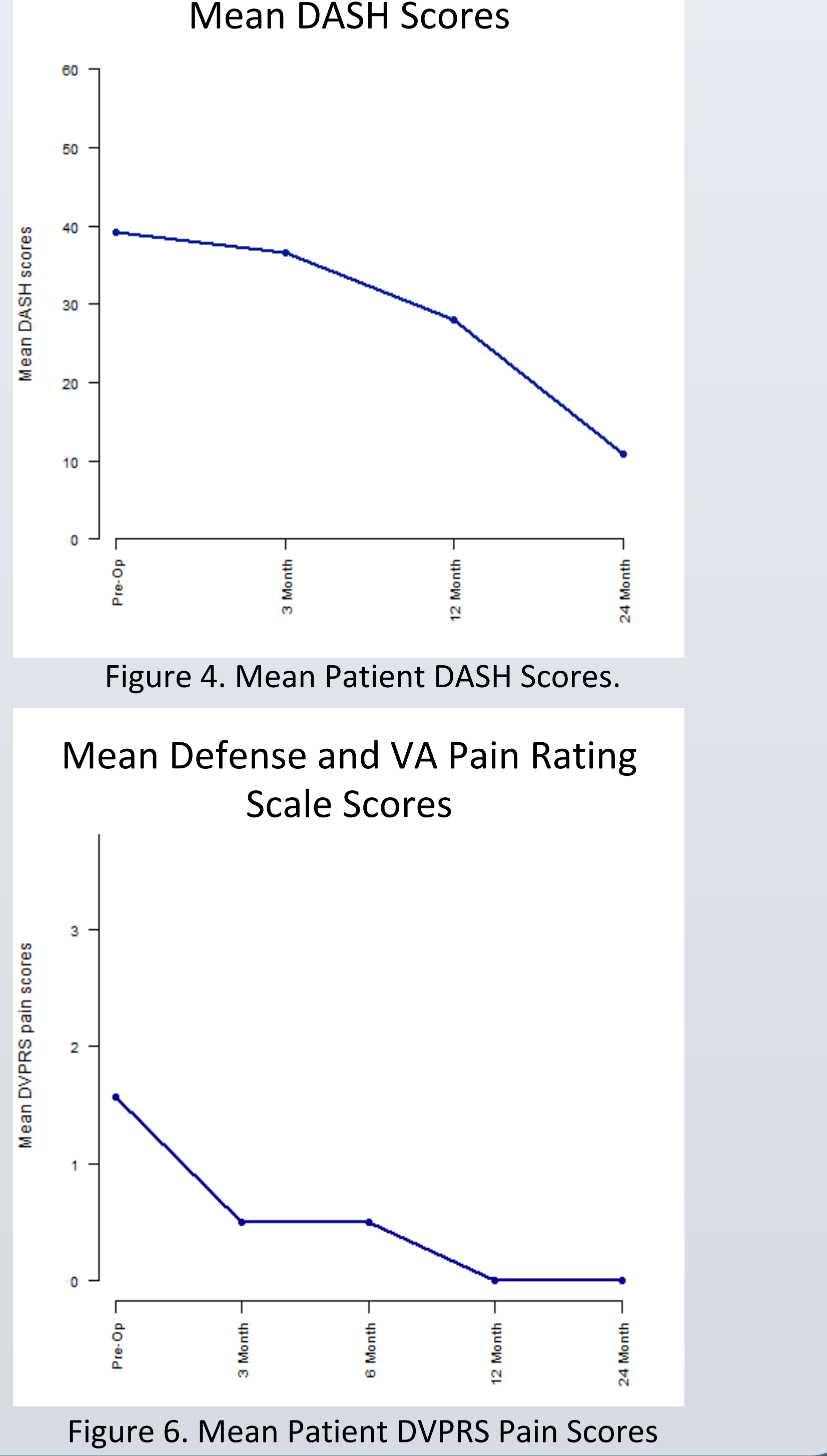

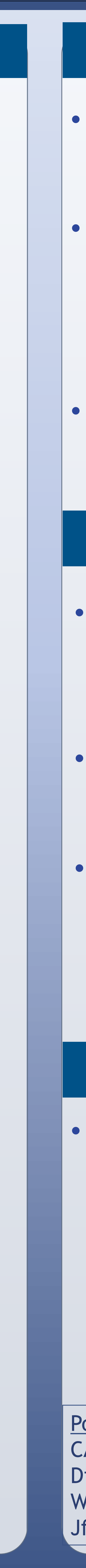

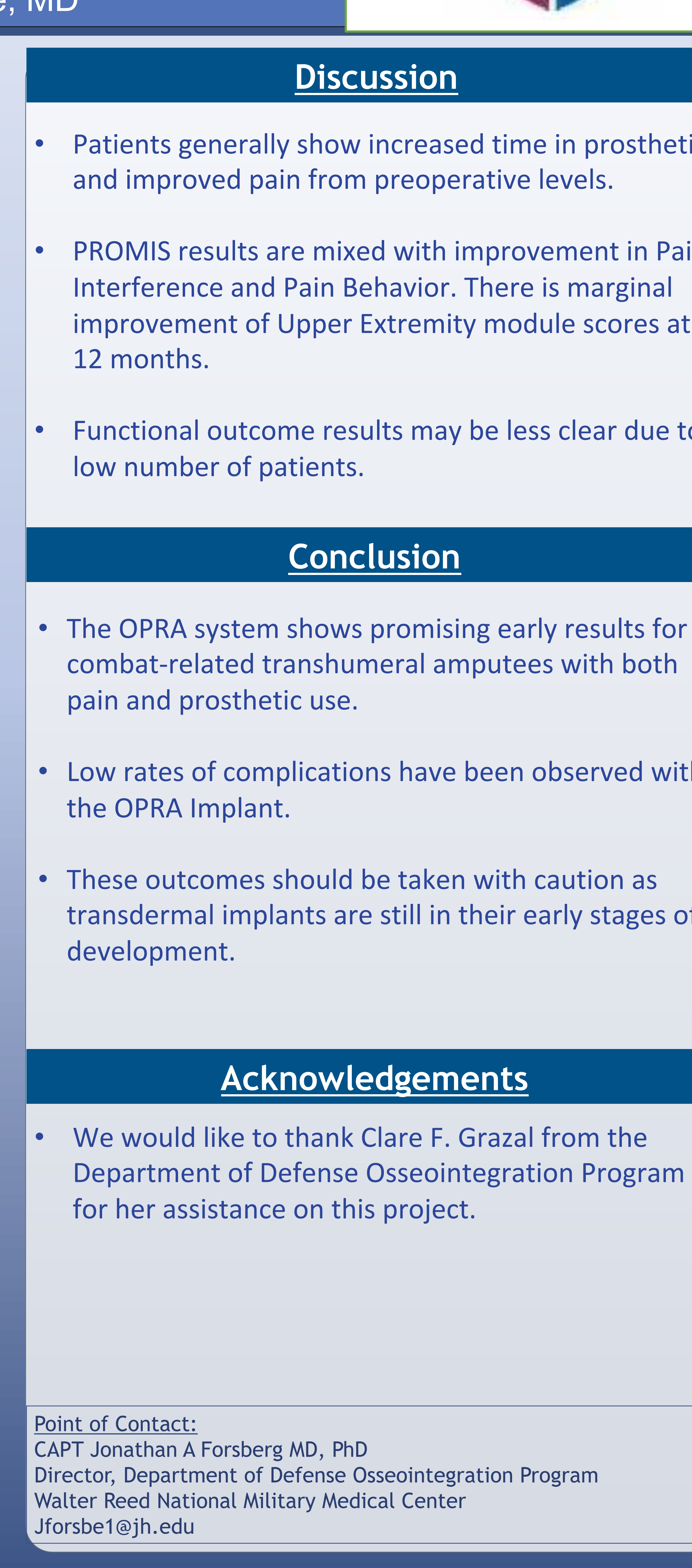

